\title{
(6) OPEN ACCESS \\ Minimising the harm from nicotine use: finding the right regulatory framework
}

\author{
Ron Borland
}

\section{Correspondence to}

Dr Ron Borland, Research

Division, The Cancer Council

Victoria, 1 Rathdowne St,

Carlton, Victoria 3053,

Australia;

Ron.Borland@cancervic.org.au

Received 16 October 2012

Revised 1 January 2013

Accepted 7 January 2013
To cite: Borland R. Tob

Control 2013;22:i6-i9.

\section{ABSTRACT}

The tobacco problem can be usefully conceptualised as two problems: eliminating the most harmful forms of nicotine use (certainly cigarettes, and probably all smoked tobacco), and minimising the use and/or harms from use of lower-harm, but addictive forms of nicotine. A possible target would be to effectively eliminate use of the most harmful forms of nicotine within the next decade and then turn our focus to a long-term strategy for the low-harm forms. This paper focuses on the administrative framework(s) needed to accomplish these twin tasks. For a phase-out taking a long time and/or for dealing with residually net harmful and addictive products, there are severe limitations to allowing forprofit marketing of tobacco because such an arrangement (the current one in most countries) can markedly slow down progress and because of the difficulty of constraining marketing in ways that minimise undesirable use. A harm reduction model where the marketing is under the control of a non-profit entity (a regulated market) is required to curtail the incredible power of for-profit marketing and to allow tobacco marketing to be done in ways that further the goal of minimising tobacco-related harm. Countries with a nationalised industry can move their industry onto a harm minimisation framework if they have the political will. Countries with a for-profit industry should consider whether the time and effort required to reconstruct the market may, in the longer term, facilitate achieving their policy goals.

Getting on top of the problem of tobacco-related harm is a huge challenge. In 2004 the international community enacted WHO's Framework Convention on Tobacco Control (FCTC) as a means of enabling international cooperation to stop the epidemic. While this is leading to considerable progress, especially in countries which had previously not taken the issue seriously, ${ }^{1}$ there are concerns that in countries which are fully or close to fully compliant that rates of smoking are still high $(15 \%$ or more of daily smokers, especially among males, in whom tobacco use is typically more prevalent). ${ }^{2}$ This suggests that there may be a need for new approaches if we are to make substantially more progress. The development of new approaches can benefit from a coherent analysis of the nature of the system supporting tobacco use.

Tobacco use is the end result of the operation of a system involving the tobacco industry, which acts to drive up use; a tobacco control movement working to reduce use; and a regulatory agency (government) setting the agenda for what can and cannot be done, in this case around an explicit goal of reducing/eliminating the harm. ${ }^{3}{ }^{4}$ These forces interact with characteristics of the individual to determine use. The analysis is grounded in two realities: that humans are susceptible to nicotine addiction and that the most attractive form of nicotine delivery to users, the modern cigarette, is also the most harmful. Tobacco control faces several systemic problems (some well-documented): (1) that while tobacco products are net harmful, any industry involved in for-profit marketing of such products is in an intrinsically antagonistic relationship with the overall system's goals; (2) the health and other costs of smoking are treated as externalities (ie, they are not dealt with within the tobacco use management system), which is is one major reason why funding for tobacco control is not commensurate with the magnitude of the problem; (3) there is a polarisation between harm reduction and use reduction approaches which may threaten effective action; (4) there is no dedicated regulatory agency to drive more effective policies in most places (the USA is the most notable exception, and even here, its powers are under constant challenge); and (5) the tobacco industry is embedded in a different higher-order system (commerce) than the health system, and because tobacco is not central to either, there is a reluctance to countenance solutions that are not consistent with accepted approaches to regulating the core elements of each system.

This paper identifies three interrelated challenges tobacco control efforts need to address: first, how best to frame the problem; second, what sorts of specific policies and practices are required; and third, what the best organisational structure for the tobacco use system to achieve the desired goals is. These need to be considered within a framework of the likely timeframe and effort required to implement specific solutions. The main focus here is on the potential of an organisational structure where the marketing of tobacco products is put in the hands of organisations with goals that are consistent with the overall aims of tobacco control, rather than being diametrically opposed, as is currently the case..$^{5-9}$ This is something I have called a regulated market. ${ }^{5}$ The value of a regulated market is that it provides a structure where the explicit goal of the marketer of tobacco products is to minimise harm, which is the same or similar goal as government policy. By contrast, this is a near impossible task for a for-profit company when the most acceptable form of tobacco for consumers (cigarettes) is also the most harmful.

The way a problem is framed affects the way people think about it, and thus the possible solutions that are canvassed. Up until recently, the implicit frame has been the elimination of tobacco use in all its forms as a unified goal using the 
framework for action developed in the 1960s and 1970s. ${ }^{10} 11$ However, over the last few years, some have questioned whether this will be enough ${ }^{2-15}$ and have argued for the consideration of new strategies. Other reasons for this shift in thinking include increasing evidence that some forms of tobacco use, particularly some forms of smokeless tobacco, while still addictive, are associated with far lower health-related harms ${ }^{16}$; and increased interest in the use of nicotine replacement therapy (NRT) for extended periods, not just as a short-term aid to quitting. Those interested in harm reduction have argued for use of NRT for long-term use and also for consideration of the use of low-toxin forms of smokeless tobacco ${ }^{12-15}$ and, more recently, e-cigarettes. ${ }^{17}$ This approach has met with heated opposition from some within tobacco control circles, especially those concerned with the problem of addiction as well as that of health harms. This discord threatens the united approach that has typified successful tobacco control efforts to date. ${ }^{4}$

It may be that a rapprochement between those who focus on harm reduction and those whose concerns run deeper to include addictive use is to reconceptualise the tobacco problem as two related problems: the harmfulness of the products when used long-term and the addictiveness of the products. Thought of this way, the solution can be similarly split: first, eliminating the most harmful forms of nicotine use (certainly cigarettes and probably all smoked tobacco) and, second, minimising the use and/or harms from the use of low-toxin, lower-harm-but still addictive-forms of nicotine.

This special issue contains commentary on a range of policy proposals for eliminating smoking and/or all forms of tobacco use more rapidly. Proposals include prohibiting cigarettes; ${ }^{18} 19$ prohibiting access to tobacco in those who do not currently use it, operationalised as banning use for those born after the year $2000 ;^{20}$ licensing remaining smokers; ${ }^{21}$ placing limits on supply ${ }^{22}$ and phasing out the nicotine from cigarettes. ${ }^{23}$ Some also allow for the prolonged use of cigarettes (for some), while others would eliminate cigarettes as a legal product quite rapidly. Whether these proposals can be considered paths to prohibition or not hangs on whether they would allow use of alternative forms of nicotine that have at least some of the desired sensory effects of smoked nicotine. Under the two-stage approach outlined above, alternative forms of nicotine could be available, at least during the period in which the reduction in smoking was occurring. If alternative forms of nicotine were allowed, in all likelihood, the more consumer-desirable the products, the greater their potential as substitutes and/or usefulness for quitting, but at the cost of greater appeal to current nonsmokers and more prolonged use. The options for such a market would be to treat any continued use of nicotine products as a form of maintenance therapy, under the control of the pharmaceutical industry and medicines regulators; to allow forprofit companies to market the low-harm products, albeit with some restrictions; or to find some intermediate mechanism, such as a regulated market.

A successful approach to achieving the first of the two suggested goals of tobacco control would be one that managed to reduce the net harm from tobacco use to within the range of harm that society accepts for other activities. Where the acceptable level would fit in this range would depend on an assessment of compensating benefits, which, if small (as is commonly assumed for tobacco use), would suggest much lower health harm should be the target. This should also be accompanied by no major increase in social harm, as might be caused if a large market for illicit tobacco arose.
An unanswered question is what level of a black market (eg, for cigarettes) governments are prepared to tolerate. Too large a black market may lead to socially unacceptable costs (this was the case for alcohol prohibition ${ }^{24}$ ) and is considered by many to be too high for other currently illegal drugs. ${ }^{25}$ If supply was countenanced, it would need to be in a form that minimised any undesirable effects, while facilitating the move away from the high-harm forms. At present, we have no clear idea of the likely size of a continuing market for high-harm products. It is likely to be affected by the range and acceptability of the substitute products available, cost and the extent of public education to support the shift.

The optimal structure for a system to manage tobacco use depends, in part, on how long it is thought that it would take to be achieved and what volume and kinds of undesirable products are still able to be marketed. For a long duration phase-out and/ or for supplying residual net harmful and addictive products, there are severe limitations on allowing for-profit marketing, both because such an arrangement (the current one in most countries) can markedly slow down progress towards reducing harm because of the difficulty of constraining marketing in ways that minimise undesirable use. If the market is in the hands of current tobacco companies, there will be a need for constant vigilance and supporting regulation to prevent actions that would undermine the policy objectives, and continual effort to counteract industry advocacy to repeal or weaken any effective actions. This inefficiency is inevitable while this is the easiest way to continue to make profits from selling tobacco products but may be a cost that needs to be borne. However, it should not be considered inevitable; there are alternatives.

There are framing and structural problems with marketing nicotine used long-term as pharmaceuticals. Doing so gives these products the status of medicines, and if the policy is to eliminate them, then this could send the wrong message, especially for products that come to be used for the experiences they provide (beyond reducing cravings to smoke). Some candidate products clearly do this (eg, low-toxin smokeless tobacco and e-cigarettes, as may some forms of NRT such as mouth spray). Furthermore, treating substitutes as therapy provides no framework for dealing with any black market.

A regulated market represents the theoretically optimal systemic framework to facilitate whatever policy option above is implemented. The essence of such a model is that within any market, an agency with a harm reduction charter has a monopoly on the marketing of tobacco products. This eliminates competition to grow market share, and because profit is not linked to sales, it minimises incentives to otherwise grow the market and/or undermine tobacco control policies. Because the agency that supplies tobacco can then become the effective regulator, it is likely to be more adroit than an agency regulating from outside. It can set product standards, encourage product innovations that are consistent with its goals and can effectively control distribution (as it determines where and when products can be sold by the outlets it supplies to). It is a structure that can provide (unconstrained by conflicts of interest) advice and support for cessation at point of sale. It also has the capacity to provide more detailed surveillance of use (it knows exactly what was distributed and when), which, in turn, allows more sensitive and rapid changes in its practices to achieve its goals. ${ }^{5}$

A regulated market makes some forms of supply of high-harm tobacco products feasible with minimal risks of it leading to a winding back of gains, if this is necessary to control illicit trade. Prices and availability of legally available products can be 
controlled to maximise the value equation between levels of legal and illicit use in ways that minimise total use and/or total harm.

In general terms, there are costs associated with changing organisations or supra-organisational systems (especially where such changes are likely to be highly contested, as in this case). Furthermore, there appears to be reluctance from governments to take on the responsibility. As a consequence, it may only be worthwhile considering a regulated market where there are major problems and/or the problems are likely to remain for a considerable length of time. Thus the optimal structure for tobacco control will be dependent on the speed of the likely change, the potential for action to undermine the policy objective by those who have vested interests in a continuation of the status quo, and the size and nature of the residual problem. Experience of tobacco control initiatives to date has shown that the tobacco industry (or sections of it) have resisted the introduction of potentially effective tobacco control policies and, once announced, have litigated to slow or prevent policy initiatives and/or have acted to minimise their effects. ${ }^{26} 27$

The alternative of pursing new initiatives, such as some forms or mixes of the solutions that have been canvassed in this special issue, is an elaboration of the current approach where there is a gradual squeezing of the tobacco market through a combination of restrictions on smoking, taxation, further restrictions on promotion and marketing, some regulation of products, and continuing public education and support programmes for cessation. Under this scenario, there will be a lot of tobacco use for many more years, even according to the most optimistic estimates. Given the capacity of the industry to slow and subvert such efforts, there is little doubt that a regulated market would result in faster progress, once the fight to establish it was wonby no means a trivial proviso, as the fight would be a big one.

Of the options canvassed at this meeting, perhaps the most promising strategy is some form of the Benowitz and Henningfield model, ${ }^{23}$ which is to act to make current cigarettes less attractive by simplifying them and reducing their nicotine deliveries to non-addictive levels, while providing as wide a range of less harmful alternatives as possible. Such a strategy would benefit greatly from a regulated market as it could effectively control the low-harm market and deal with any residual need to supply ordinary cigarettes to those resistant to alternatives.

A regulated market would not be needed if there was no need to supply any forms of high-harm tobacco products (to control the illicit market) and there was no longer any major societal concern about levels of use of low-harm forms; that is, if society became satisfied that the residual harms were sufficiently counterbalanced by the benefits of continued availability and use. Unless this happens, and achieving both these criteria is unlikely, active consideration of how tobacco products are marketed should be a central part of considering long-term solutions.

A harm reduction model where the marketing is under the control of a non-profit entity would curtail the incredible power of for-profit marketing and could allow those marketing tobacco under the revised incentive scheme to become genuine partners in the goal of minimising tobacco-related harm. Governments seem wary of the idea, possibly because of its novelty and uncertainly as to the political implications of being seen to be the supplier of harmful products. Countries with a nationalised industry can move their industry onto a harm minimisation framework, if they have the political will. Countries with a forprofit industry should consider whether the time and effort required to reconstruct the market may, in the longer term, facilitate achieving their policy goals.

\section{Key messages}

- Reconceptualising the tobacco problem into seeking two related goals may help resolve tensions in the tobacco control community.

- First, attempting to eliminate the most harmful forms of tobacco use.

- Second, managing the remaining tobacco and nicotine use problem.

- A regulated market approach could facilitate achieving these goals.

Funding RWJF Health Policy Research Scholar's Program.

\section{Competing interests None.}

Provenance and peer review Commissioned; externally peer reviewed.

Open Access This is an Open Access article distributed in accordance with the Creative Commons Attribution Non Commercial (CC BY-NC 3.0) license, which permits others to distribute, remix, adapt, build upon this work non-commercially, and license their derivative works on different terms, provided the original work is properly cited and the use is non-commercial. See: http://creativecommons.org/ licenses/by-nc/3.0/

\section{REFERENCES}

1 WHO. WHO report on the global tobacco epidemic. Geneva: WHO, 2011.

2 Warner KE, Mendez D. Tobacco control policy in developed countries: yesterday, today and tomorrow. Nicotine Tob Res 2010;12:876-87.

3 Borland $R$, Young D, Coghill $K$, et al. The tobacco use management system: analyzing tobacco control from a systems perspective. Am J Public Health 2010;100:1229-36.

4 Young D, Borland R, Coghill K. Changing the tobacco use management system: blending systems thinking with Actor-Network Theory. Rev Policy Res 2012:29:251-79.

5 Borland R. A strategy for controlling the marketing of tobacco products: s regulated market model. Tob Control 2003;4:374-82.

6 Borland R. Taming the tigers: the case for controlling the tobacco market. Addiction 2004:99:529-31

7 Borland R. Why not seek clever regulation? Tob Control 2006;15:339-40.

8 Borland R. The need for new strategies to combat the epidemic of tobacco-related harm. Tob Control 2012;12:287-8.

9 Callard C, Thompson D, Collishaw N. Curing the addiction to profits: a supply-side approach to phasing out tobacco. Ottawa: Canadian Centre for Policy Alternatives, 2005.

10 Royal College of Physicians. Smoking and health: summary of a report of the Royal College of Physicians of London on smoking in relation to cancer of the lung and other diseases. London: Pitman, 1962.

11 Gray N, Daube M. Guidelines for smoking control. Geneva: International Union Against Cancer, 1976.

12 Henningfield JE, Fagerstrom KO. Swedish Match Company, Swedish snus and public health: a harm reduction experiment in progress? Tob Control 2001;10:253-7.

13 Sweanor D, Alcabes P, Drucker E. Tobacco harm reduction: how rational public policy could transform a pandemic. Int J Drug Policy 2007;18:70-4.

14 Royal College of Physicians. Harm reduction in nicotine addiction: helping people who can't quit. A report by the Tobacco Advisory Group of the Royal College of Physicians. London: RCP, 2007.

15 Borland R. Harm reduction for smokers: targeting those who don't quit. In: Moore D, Dietz P, eds. Drugs and public health: Australian perspectives on policy and practice. Melbourne: Oxford University Press (ANZ), 2008: 85-93.

16 Levy DT, Mumford EA, Cummings KM, et al. The relative risks of a lowv nitrosamine smokeless tobacco product compared with smoking cigarettes: estimates of a panel of experts. Cancer Epidemiol Biomarkers Prev 2004;13:2035-42.

17 Borland R. Electronic cigarettes as a method of tobacco control. Editorial. BMJ 2011;343:d6269.

18 Daynard RA. Doing the unthinkable (and saving millions of lives). Tob Control 2009;18:2-3. 
19 Proctor RN. Golden holocaust: origins of the cigarette catastrophe and the case for abolition. 1st edn. Berkeley: University of California Press, 2012.

20 Khoo D, Chiam Y, Ng P, et al. Phasing-out tobacco: proposal to deny access to tobacco for those born from 2000. Tob Control 2010;19:355-360.

21 Chapman S. The case for a smoker's license. PLoS Med 2012:9:e1001342.

22 Thomson G, Wilson N, Blakely $\mathrm{T}$, et al. Ending appreciable tobacco use in a nation: using a sinking lid on supply. Tob Control 2010;19:431-5.

23 Benowitz NL, Henningfield JE. Establishing a nicotine threshold for addiction. The implications for tobacco regulation. N Engl J Med 1994;331:123-5.
24 Levine $\mathrm{HG}$, Reinarman $\mathrm{C}$. Alcohol prohibition and drug prohibition: lessons from alcohol policy for drug policy. In: Fish JM, eds. Drugs and society: US public policy. Lanham, MD: Rowman \& Littlefield, 2006

25 Reuter P. Can tobacco control endgame analysis learn anything from the US experience with illegal drugs? Tob Control 2013:22:i49-i51.

26 Borland $\mathrm{R}$, Winstanley $\mathrm{M}$, Reading $\mathrm{D}$. Legislation to institutionalize resources for tobacco control: the 1987 Victorian Tobacco Act. Addiction 2009;104:1623-9.

27 WHO. Tobacco industry interference with tobacco control. Geneva: WHO, 2008. 